\title{
Rivaroxaban for venous thromboembolism prevention after major orthopedic surgery: translating trial data into routine clinical practice
}

This article was published in the following Dove Press journal:

Orthopedic Research and Reviews

31 January 2017

Number of times this article has been viewed

\author{
Jan Beyer-Westendorf ${ }^{\prime}$ \\ Patrick Mouret ${ }^{2}$ \\ Alexander GG Turpie 3 \\ 'Thrombosis Research and Angiology, \\ Dresden University Clinic, Dresden, \\ Germany; ${ }^{2}$ Orthopedic Clinic, \\ Klinikum Frankfurt Höchst GmbH, \\ Frankfurt, Germany; ${ }^{3}$ Department \\ of Medicine, General Division, \\ Hamilton Health Sciences, Hamilton, \\ ON, Canada
}

Correspondence: Jan Beyer-Westendorf Thrombosis Research and Angiology, Medical Clinic III, Dresden University Clinic, 74 Fetscherstrasse, Dresden

01307 , Germany

Tel +493514583659

Fax +493514584359

Email jan.beyer@uniklinikum-dresden.de

\begin{abstract}
An established standard of care for the prevention of venous thromboembolism after major orthopedic surgery has been subcutaneous low-molecular-weight heparin. The non-vitamin $\mathrm{K}$ antagonist oral anticoagulant rivaroxaban has demonstrated superior efficacy and similar safety to all tested regimens of enoxaparin in large Phase III clinical studies of venous thromboembolism prevention after elective hip and knee arthroplasty. Despite regulatory approval of rivaroxaban for this indication, concerns remain among physicians regarding its optimal and effective use in routine clinical practice. Real-life studies, such as XAMOS and ORTHO-TEP, are providing physicians with more information on the routine use of rivaroxaban for venous thromboembolism prevention after orthopedic surgery, helping to establish its safety and effectiveness in everyday clinical care. Among the most important issues are the risk of bleeding complications, wound healing, timing of first dose, impact of type of anesthesia on thromboprophylaxis effectiveness, patient comorbidities and comedication use, periprocedural management, associated costs, and clinical outcomes in trauma-related fractures. Many of these issues are difficult to study in randomized, double-blind, Phase III trials, and can be assessed more readily using real-life data. In particular, real-life or noninterventional studies lack many of the strict inclusion and exclusion criteria associated with Phase III trials and involve unselected patients who often present with significant comorbidities or comedication use.
\end{abstract}

Keywords: anticoagulants, arthroplasty, orthopedics, rivaroxaban, thrombosis

\section{Introduction}

Major orthopedic surgery is a risk factor for the development of venous thromboembolism (VTE), which includes deep vein thrombosis (DVT) and pulmonary embolism. Without effective thromboprophylaxis, approximately half of patients undergoing hip or knee arthroplasty develop asymptomatic DVT, and up to $2 \%$ may experience a fatal pulmonary embolism. ${ }^{1}$ Consequently, thromboembolic events postsurgery result in a burden on health care resources, in addition to considerable morbidity and mortality. ${ }^{2}$ An established standard of care (SOC) for VTE prevention in patients after orthopedic surgery has been a subcutaneous anticoagulant (eg, low-molecular-weight heparin [LMWH] or to a lesser extent fondaparinux), followed by a vitamin $\mathrm{K}$ antagonist or acetylsalicylic acid. ${ }^{1}$ All of these agents have limitations, and the potential advantages of the non-vitamin K antagonist novel oral anticoagulants (NOACs; eg, apixaban, dabigatran, and rivaroxaban) led to their evaluation for VTE prevention after elective hip- and knee-replacement surgery. ${ }^{3}$

Rivaroxaban is an oral, direct factor Xa inhibitor that is approved globally for the prevention of VTE after elective hip and knee arthroplasty, based on results of the 
large Phase III RECORD program; in some countries, it has a broader label to include use after lower-limb orthopedic surgery. ${ }^{4-8}$ Despite widespread approval, there are still outstanding questions from clinicians relating to the everyday use of rivaroxaban. These questions relate to the optimal duration of thromboprophylaxis after surgery; its use with other medications; the risk of adverse events, such as bleeding or wound-related complications; the optimal timing of the first thromboprophylactic dose; periprocedural care of the anticoagulated patient; use with general and regional anesthesia; and use in fracture-related cases. ${ }^{9,10}$

Data from Phase III studies that led to the approval of a drug may not directly apply to patients in everyday care, but in the case of rivaroxaban, increasing real-life experience in VTE prevention after orthopedic surgery is providing insights into optimal patient treatment, improved physician knowledge, and future best-management practice. ${ }^{1-14}$ Noninterventional, observational studies are helpful in establishing the effectiveness of drugs in unselected patients in routine clinical practice, and such studies can provide information on aspects that are difficult to assess in randomized clinical trial settings. Using a Medline search to draw on data from real-life studies of rivaroxaban for VTE prevention, this review aims to summarize current knowledge in areas that are relevant to orthopedic surgeons, anesthesiologists, and other health care professionals related to routine rivaroxaban thromboprophylaxis after major orthopedic surgery.

\section{Introduction to recent studies}

The RECORD program comprised four double-blind, randomized Phase III studies against an active comparator, and investigated the safety and efficacy of rivaroxaban (10 mg once daily, begun 6-8 hours postoperatively) compared with enoxaparin for the prevention of VTE after elective total hip arthroplasty (THA; RECORD1 and RECORD2) and elective total knee arthroplasty (TKA; RECORD3 and RECORD4). ${ }^{4-7}$ A total of 12,729 patients scheduled for elective surgery were randomized to receive either rivaroxaban (10 $\mathrm{mg}$ once daily) or enoxaparin (40 mg once daily [RECORD1-3] or $30 \mathrm{mg}$ twice daily [RECORD4]). Incidences of the composite of symptomatic VTE, all-cause mortality, and major bleeding events in the pooled analysis of the four RECORD studies are shown in Table $1 .{ }^{8}$ Compared with enoxaparin, rivaroxaban was shown to reduce the composite of symptomatic VTE and all-cause mortality after elective THA/TKA surgery $(0.6 \%$ versus $1.3 \%)$ significantly, with a small, nonsignificant increase in major bleeding $(0.4 \%$ versus $0.2 \%)$ and no other unexpected safety signals. ${ }^{8}$

The strict inclusion and exclusion criteria and high levels of medical supervision required for patients in randomized trials may not be reflective of the treatment received by patients in everyday routine practice. As a consequence, the large, prospective, noninterventional XAMOS cohort study was initiated to assess the safety and effectiveness of rivaroxaban after major orthopedic surgery in unselected patients in routine clinical practice. ${ }^{11}$ A total of 17,701 patients from 37 countries were enrolled in XAMOS, in which the frequency of adverse events, including symptomatic thromboembolic and bleeding events, was recorded in patients receiving rivaroxaban or any other approved form of thromboprophylaxis (defined as SOC) after major orthopedic surgery. Patients treated with rivaroxaban had a significantly lower incidence of symptomatic VTE compared with those receiving SOC $(0.7 \%$ versus $1 \%)$. These results were consistent with the findings from the RECORD

Table I Key clinical outcomes from the RECORD and XAMOS studies

\begin{tabular}{|c|c|c|c|c|c|c|}
\hline \multirow[t]{2}{*}{ Outcome } & \multicolumn{3}{|c|}{ RECORD I-4 pooled ${ }^{8, a, b}$} & \multicolumn{3}{|l|}{ XAMOS $^{1,, c}$} \\
\hline & $\begin{array}{l}\text { Rivaroxaban } \\
(\mathrm{N}=6,183)\end{array}$ & $\begin{array}{l}\text { Enoxaparin } \\
(N=6,200)\end{array}$ & OR $(95 \% \mathrm{Cl})$ & $\begin{array}{l}\text { Rivaroxaban } \\
(\mathrm{N}=\mathbf{8 , 7 7 8 )}\end{array}$ & $\operatorname{SOC}(\mathbf{N}=8,635)$ & OR $(95 \% \mathrm{Cl})$ \\
\hline Symptomatic VTE, \% (n) & $0.45(28)$ & I.I (68) & $0.4^{\mathrm{d}}(0.26-0.64)$ & $0.65(57)$ & $1.02(88)$ & $0.63(0.45-0.89)$ \\
\hline All-cause mortality, \% (n) & $0.13(8)$ & $0.26(16)$ & $0.5^{\mathrm{d}}(0.2 \mathrm{I}-\mathrm{I} .16)$ & $0.08(7)$ & $0.09(8)$ & $0.86(0.31-2.37)$ \\
\hline Major bleeding, \% $(n)^{b, e}$ & $0.39(24)$ & $0.21(13)$ & $1.84(0.94-3.62)$ & $0.4(35)$ & $0.34(29)$ & $1.19(0.73-1.95)$ \\
\hline Leading to reoperation & $0.19(12)$ & $0.11(7)$ & ND & $0.31(27)$ & $0.21(18)$ & ND \\
\hline All other serious AEs, \% (n) & $6.57(406)$ & $8.52(528)$ & ND & $3.09(27 I)$ & $3(259)$ & ND \\
\hline \multicolumn{7}{|l|}{ Wound complications, \% (n) } \\
\hline Postoperative wound infection & $0.44(27)$ & $0.45(28)$ & ND & $0.15(13)$ & $0.08(7)$ & $\mathrm{I} .83(0.68-5.4 \mathrm{I})$ \\
\hline Postoperative wound discharge & $0.1(6)$ & $<0.1(3)$ & ND & $0.42(37)$ & $0.12(10)$ & $3.65(1.78-8.24)$ \\
\hline Hemorrhagic wound complications $s^{f}$ & $1.62(100)$ & $1.69(105)$ & ND & $0.47(4 I)$ & $0.42(36)$ & $1.12(0.7 \mathrm{I}-1.76)$ \\
\hline
\end{tabular}

Notes: aSafety population, total treatment-duration pool; ${ }^{\mathrm{b}}$ period of data collection was the total treatment-duration pool, defined as the planned treatment period for the double-blind study medication for each RECORD study; 'safety population; dhazard ratio; eRECORD major bleeding definition; ffor total treatment-duration pool, RECORD and XAMOS - treatment-emergent hemorrhagic wound complications.

Abbreviations: $\mathrm{AE}$, adverse event; $\mathrm{Cl}$, confidence interval; ND, not determined; OR, odds ratio; SOC, standard of care; VTE, venous thromboembolism. 
program (Table 1). ${ }^{8}$ The incidences of major bleeding events defined using the RECORD bleeding definition (fatal bleeding; bleeding into a critical organ, eg, retroperitoneal, intracranial, intraocular, or intraspinal bleeding; or bleeding requiring reoperation or extrasurgical site bleeding that was clinically overt and associated with a drop in hemoglobin levels of $\geq 2 \mathrm{~g} / \mathrm{dL}$ or that required transfusion of $\geq 2$ units of whole-blood or packed cells) were low and similar between the rivaroxaban- and SOCtreatment groups in XAMOS $(0.4 \%$ versus $0.3 \%)$. The frequency of other adverse events (including wound infection and wound hemorrhage) was also similar between the two treatment groups. A propensity score-adjusted analysis was also undertaken, using subclasses of similar propensity scores estimated from pretreatment baseline characteristics. In contrast to the results seen in the "crude" unadjusted analysis, the rate of major bleeding (European Medicines Agency [EMA] definition) was higher for rivaroxaban compared with $\mathrm{SOC},{ }^{11}$ which was driven by a higher rate of bleeding that led to treatment cessation. However, a bleeding event that warrants treatment cessation is no longer considered a sole criterion for major bleeding by the EMA, because treatment cessation may be decided based on subjective factors other than the actual severity of bleeding. ${ }^{15}$ Taken together, the results of the XAMOS study confirmed the favorable benefit-risk profile of rivaroxaban seen in RECORD, suggesting that in routine clinical practice, rivaroxaban has the potential to assist physicians in improving thromboprophylaxis in patients after major orthopedic surgery. ${ }^{8,11}$

ORTHO-TEP, a real-life retrospective analysis, compared the efficacy and safety of rivaroxaban (used in $20.6 \%$ of all patients) with that of fondaparinux (in $39.4 \%$ of patients) or LMWH (in 29.5\% of patients) for VTE prophylaxis after major orthopedic surgery. ${ }^{16,17}$ These three drugs were studied in consecutive cohorts between 2006 and 2011, and the choice of anticoagulant therapy was based on the hospital SOC at the time of treatment. Analysis was based on patient charts, a quality-management database, a hospital admission and discharge database, a transfusion-unit database, and VTE-event documentation. Although the retrospective and single-center design of ORTHO-TEP limits direct efficacy comparisons with the RECORD studies and XAMOS, overall findings were similar, with lower rates of symptomatic VTE reported in patients receiving rivaroxaban compared with those receiving LMWH (2.1\% versus $4.1 \%, P<0.001$ ) (Table 2). ${ }^{17}$ Additionally, when compared with fondaparinux, rivaroxaban was associated with fewer symptomatic venous thromboembolic events $(2.1 \%$ versus $5.6 \%, P<0.001) .{ }^{16}$ Importantly, this cohort study did not identify an increased risk of bleeding complications in patients treated with rivaroxaban. Within the limitations of retrospective bleeding assessments, in which the exact classification of bleeding events is difficult, the incidence of major bleeding (bleeding occurring in a critical site or leading to surgical revision or death, or transfusion of $\geq 2$ units of packed red blood cells) was lower with rivaroxaban compared with LMWH $(2.9 \% \text { versus } 7.0 \%, P<0.001)^{17}$ or fondaparinux $(2.9 \%$ versus $4.9 \%, P=0.01){ }^{16}$

A recent, large, retrospective Canadian study of 24,321 patients aged over 66 years analyzed rates of hospitalization for VTE and for major bleeding (subarachnoid, intracerebral, and upper and lower gastrointestinal tracts) in the 30-day period after prescription of LMWH or rivaroxaban for THA or TKA surgery. ${ }^{18}$ The study data, derived from 121 centers in Ontario between 2002 and 2012, showed that venous thromboembolic events were observed significantly less frequently with rivaroxaban compared with LMWH $(0.47 \%$ versus $0.81 \%, P=0.001)$, with similar rates of major bleeding $(0.18 \%$ versus $0.2 \%, P=0.700)$ (Table 3$).{ }^{18}$ Findings were similar within 90 days, and did not differ substantially after adjustment for age, sex, hospital setting, history of cancer, and type of orthopedic surgery. ${ }^{18}$

A number of smaller, prospective, retrospective, and observational studies have also addressed the safety and effectiveness of rivaroxaban, usually in comparison with SOC. Results of these studies are summarized in Table 3.

Table 2 Key clinical outcomes from ORTHO-TEP

\begin{tabular}{|c|c|c|c|c|c|c|}
\hline \multirow[t]{2}{*}{ Outcome } & \multicolumn{2}{|c|}{ Rivaroxaban $(\mathbf{N}=1,043)$} & \multicolumn{2}{|c|}{ LMWH $(\mathbf{N}=1,495)$} & \multicolumn{2}{|c|}{ Fondaparinux $(\mathbf{N}=I, 994)$} \\
\hline & $\%(n)$ & $95 \% \mathrm{Cl}$ & $\%(n)$ & $95 \% \mathrm{Cl}$ & $\%(n)$ & $95 \% \mathrm{Cl}$ \\
\hline Symptomatic VTE & $2.11(22)$ & $1.32-3.18$ & $4.15(62)$ & $3.19-5.29$ & $5.62(1 \mid 2)$ & $4.65-6.72$ \\
\hline All-cause mortality & $0.19(2)$ & $0.02-0.69$ & $0.07(1)$ & $0.0017-0.37$ & $0.15(3)$ & $0.03-0.44$ \\
\hline Major bleeding & $2.88(30)$ & $1.95-4.08$ & $7.02(105)$ & $5.78-8.44$ & $4.86(97)$ & $3.96-5.9$ \\
\hline Surgical revisions due to bleeding complications & $0.38(4)$ & $0.10-0.98$ & I.34 (20) & $0.82-2.06$ & I.I (22) & $0.69-1.67$ \\
\hline Any surgical revision & $1.15(12)$ & $0.6-2$ & $3.68(55)$ & $2.78-4.76$ & $1.65(33)$ & $1.14-2.32$ \\
\hline
\end{tabular}

Notes: Adapted from: Beyer-Westendorf J, Lützner J, Donath L, et al. Efficacy and safety of rivaroxaban or fondaparinux thromboprophylaxis in major orthopedic surgery: findings from the ORTHO-TEP registry. J Thromb Haemost. 2012;10(I0):2045-2052. (C) 2012 International Society on Thrombosis and Haemostasis. ${ }^{16}$ And adapted from: Beyer-Westendorf J, Lützner J, Donath L, et al. Efficacy and safety of thromboprophylaxis with low-molecular-weight heparin or rivaroxaban in hip and knee replacement surgery. Thromb Haemost. 2013;109(I):154-163. (C) 2013 Schattauer Publishers, Stuttgart. ${ }^{17}$

Abbreviations: $\mathrm{Cl}$, confidence interval; LMWH, low-molecular-weight heparin; VTE, venous thromboembolism. 
Table 3 Summary of other rivaroxaban studies

\begin{tabular}{|c|c|c|c|}
\hline Study & Design, numbers & Comparator drug & Key findings \\
\hline $\begin{array}{l}\text { Rates of hospitalization for VTE and } \\
\text { major bleeding after THA/TKA in } \\
\text { patients }>66 \text { years of age }{ }^{18}\end{array}$ & $\begin{array}{l}\text { Multicenter } \\
\text { retrospective, } \\
\mathrm{N}=24,321\end{array}$ & LMWH & $\begin{array}{l}\text { VTE was significantly less frequent with rivaroxaban } \\
\text { compared with LMWH, with similar rates of major } \\
\text { bleeding }\end{array}$ \\
\hline $\begin{array}{l}\text { Comparison of surgically relevant } \\
\text { wound complications in patients } \\
\text { undergoing prophylaxis after } \\
\text { THA/TKA }{ }^{13}\end{array}$ & $\begin{array}{l}\text { Multicenter } \\
\text { prospective, } \\
\mathrm{N}=2,762\end{array}$ & LMWH & $\begin{array}{l}\text { Patients in the rivaroxaban group had a significantly } \\
\text { higher wound-complication rate and lower DVT rate } \\
\text { than those in the LMWH group, with no significant } \\
\text { differences in PE or all-cause mortality }\end{array}$ \\
\hline $\begin{array}{l}\text { Effect of rivaroxaban prophylaxis on } \\
\text { return-to-theater rates following } \\
\text { THA/TKA }{ }^{12}\end{array}$ & $\begin{array}{l}\text { Single-center } \\
\text { retrospective, } \\
\mathrm{N}=1,048\end{array}$ & Tinzaparin & $\begin{array}{l}\text { Return-to-theater rate was significantly higher with } \\
\text { tinzaparin than with rivaroxaban }\end{array}$ \\
\hline $\begin{array}{l}\text { Rivaroxaban use in patients after } \\
\text { THA/TKA in "everyday life" } 20\end{array}$ & $\begin{array}{l}\text { Nonrandomized } \\
\text { controlled, } \mathrm{N}=1,028\end{array}$ & LMWH & $\begin{array}{l}\text { Rivaroxaban was more effective than weight-adjusted } \\
\text { nadroparin in preventing VTE after THA/TKA }\end{array}$ \\
\hline $\begin{array}{l}\text { Rates of } \mathrm{PE} \text { recurrence and } \\
\text { return-to-theater complications } \\
\text { after } \mathrm{TKA}^{30}\end{array}$ & $\begin{array}{l}\text { Single-center } \\
\text { retrospective, } \\
\mathrm{N}=862\end{array}$ & Enoxaparin $40 \mathrm{mg}$ once daily & $\begin{array}{l}\text { Significant reduction in the rate of } \mathrm{PE} \text { with } \\
\text { rivaroxaban compared with control but an increase } \\
\text { in return-to-theater rates }\end{array}$ \\
\hline $\begin{array}{l}\text { Efficacy and safety of rivaroxaban } \\
\text { vs bemiparin in extended VTE } \\
\text { prophylaxis }^{50}\end{array}$ & $\begin{array}{l}\text { Single-center } \\
\text { retrospective, } \\
\mathrm{N}=467\end{array}$ & Bemiparin 3,500 IU IV/day & $\begin{array}{l}\text { Discontinuation outcomes showed that oral } \\
\text { administration promoted better treatment adherence } \\
\text { compared with subcutaneous administration }\end{array}$ \\
\hline $\begin{array}{l}\text { Comparison of return-to-theater } \\
\text { complications after THA/TKA with } \\
\text { rivaroxaban vs enoxaparin }{ }^{14}\end{array}$ & $\begin{array}{l}\text { Single-center } \\
\text { retrospective, } \\
\mathrm{N}=387\end{array}$ & Enoxaparin $40 \mathrm{mg}$ once daily & $\begin{array}{l}\text { No significant difference in wound complications } \\
\text { between groups }\end{array}$ \\
\hline $\begin{array}{l}\text { Rate of postoperative wound } \\
\text { complications in patients undergoing } \\
\text { prophylaxis after THA }\end{array}$ & $\begin{array}{l}\text { Single-center } \\
\text { retrospective, } \\
\mathrm{N}=258\end{array}$ & Enoxaparin $40 \mathrm{mg}$ once daily & $\begin{array}{l}\text { Rivaroxaban showed no significant difference in the } \\
\text { incidence of VTE or major bleeding but did show a } \\
\text { trend toward increased rate of wound complications }\end{array}$ \\
\hline $\begin{array}{l}\text { Comparison of rivaroxaban and } \\
\text { enoxaparin after minimally invasive } \\
\text { TKA surgery }\end{array}$ & $\begin{array}{l}\text { Retrospective, } \\
\mathrm{N}=113\end{array}$ & $\begin{array}{l}\text { Enoxaparin } 20 \mathrm{mg} \text { every } \\
12 \text { hours (plus all patients } \\
\text { received tranexamic acid } \\
10 \mathrm{mg} / \mathrm{kg} \mathrm{IV} \text { ) }\end{array}$ & $\begin{array}{l}\text { No differences in postoperative hemoglobin } \\
\text { levels, blood-drainage amount, total blood loss, or } \\
\text { transfusion rate between rivaroxaban and enoxaparin } \\
\text { were found; no VTE event or major wound } \\
\text { complications occurred in either group }\end{array}$ \\
\hline $\begin{array}{l}\text { Efficacy of rivaroxaban in } \\
\text { preventing VTE after pelvic } \\
\text { trauma with immediate/delayed } \\
\text { thromboprophylaxis }{ }^{21}\end{array}$ & $\begin{array}{l}\text { Single-center } \\
\text { retrospective, } N=84\end{array}$ & $\begin{array}{l}\text { Delayed thromboprophylaxis } \\
\text { with rivaroxaban } 10 \mathrm{mg}\end{array}$ & $\begin{array}{l}\text { Patients receiving rivaroxaban thromboprophylaxis } \\
\text { soon after fracture had a lower incidence than if } \\
\text { delayed; rivaroxaban did not increase intra- or } \\
\text { postoperative bleeding in surgical wounds }\end{array}$ \\
\hline $\begin{array}{l}\text { Effect of tranexamic acid on blood } \\
\text { loss with rivaroxaban treatment after } \\
\text { orthopedic surgery }\end{array}$ & $\begin{array}{l}\text { Single-blind } \\
\text { prospective, } N=70\end{array}$ & $\begin{array}{l}\text { Rivaroxaban } 10 \mathrm{mg} \text { once } \\
\text { daily (tranexamic acid I } \mathrm{g} \\
\mathrm{IV} \text { ) was added to one group } \\
\text { of patients receiving the } \\
\text { rivaroxaban } 10 \mathrm{mg} \text { dose }\end{array}$ & $\begin{array}{l}\text { Tranexamic acid significantly reduced blood loss } \\
\text { without increasing the risk of VTE }\end{array}$ \\
\hline
\end{tabular}

Note: Experimental dose in each study: rivaroxaban $10 \mathrm{mg}$ once daily.

Abbreviations: DVT, deep vein thrombosis; IV, intravenous; LMWH, low-molecular-weight heparin; PE, pulmonary embolism; THA, total hip arthroplasty; TKA, total knee arthroplasty; VTE, venous thromboembolism.

\section{Addressing concerns of orthopedic surgeons when using non-vitamin $\mathrm{K}$ antagonist oral anticoagulants Risk of bleeding complications}

The bleeding risk associated with anticoagulant treatment after orthopedic surgery is a concern for surgeons. Major bleeding events can result in deterioration of patient condition, readmission, or extension of hospital stay. The risk of bleeding in each patient must be assessed individually to minimize adverse events. Nonmajor clinically relevant bleeding events and the need for reoperation are also important considerations when assessing the benefits of anticoagulation in patients undergoing orthopedic surgery. These adverse events can influence overall outcomes and patient quality of life. As stated earlier, rivaroxaban was shown to be as safe as SOC (mostly LMWH) in a number of studies with very different trial designs. Rates of major bleeding were similar in four prospective randomized controlled trials (RECORD1-4; Table 1$),{ }^{8}$ and were similar to SOC in the prospective reallife XAMOS study (Table 1). ${ }^{11}$ Furthermore, rates of critical bleeding (including intracranial, retroperitoneal, intraocular, and intraspinal bleeding) were 0 in the rivaroxaban group and $<0.1 \%$ in the SOC group. ${ }^{11}$ Bleeding leading to reoperation occurred in $0.3 \%$ versus $0.2 \%$ of patients in the rivaroxaban and SOC groups, respectively. ${ }^{11}$ 
In addition, a number of observational studies have investigated bleeding risk associated with rivaroxaban use in real-life practice (Tables 2 and 3). Low rates of major bleeding complications with rivaroxaban were demonstrated in the retrospective ORTHO-TEP study, both compared with LMWH and fondaparinux (Table 2). ${ }^{16,17}$ A large Canadian retrospective study found no substantial difference between rivaroxaban and LMWH in rates of hospitalization for major bleeding events at 30 and 90 days after drug prescription; however, there was a significant reduction in rates of hospitalization for venous thromboembolic events with rivaroxaban (Table 3). ${ }^{18}$

Smaller studies have also provided useful insight into bleeding complications (Table 3). In 258 patients undergoing prophylaxis after TKA/THA surgery, rivaroxaban prophylaxis was shown to have similar rates of major bleeding compared with SOC. ${ }^{19}$ Two studies investigating rivaroxaban use in patients after TKA/THA surgery $(n=1,028)$ and after pelvic trauma $(n=84)$ reported that rivaroxaban did not result in significant differences in bleeding. ${ }^{20,21}$ Data from these smaller, real-life studies provided further evidence of the consistent benefit-risk profile of rivaroxaban in patients after orthopedic surgery in routine clinical practice.

Management of bleeding has also been assessed in orthopedic patients in a single-blind, case-control study that compared the use of perioperative antifibrinolytic treatment with tranexamic acid and rivaroxaban thromboprophylaxis $(n=37)$ with rivaroxaban thromboprophylaxis alone $(n=33)$ in patients undergoing THR surgery. ${ }^{22}$ Tranexamic acid was found to reduce patient blood loss significantly without increasing the risk of VTE: these results confirmed previous data that showed the efficacy of tranexamic acid in reducing postoperative blood loss in patients, thereby decreasing the need for blood transfusions. ${ }^{23,24}$

Another observational study evaluated rates, management, and outcome of rivaroxaban-associated bleeding complications in over 1,700 daily-care patients receiving therapeutic rivaroxaban dosages for atrial fibrillation (AF) or VTE, and confirmed that major bleeding events (International Society on Thrombosis and Haemostasis definition) were low (3\%-4\%/year) and could be well controlled in most cases. ${ }^{25}$ In addition, the outcome after a rivaroxaban-associated bleeding complication requiring hospitalization was considerably better (all-cause mortality at 90 days postbleeding, $6.3 \%$ ) than the outcome of similar bleeding events reported for patients receiving a vitamin $\mathrm{K}$ antagonist (approximately 15\%). ${ }^{25-27}$ Taken together, several studies have consistently demonstrated the safety of rivaroxaban compared to SOC.

\section{Wound healing}

Surgical revisions and wound complications after orthopedic surgery are particular concerns of orthopedic surgeons, because they can result in an additional increase in bleeding risk, prolonged hospital stay, and increased reoperation rates. In the RECORD studies, there was no reported increase in wound complications with rivaroxaban compared with enoxaparin, and the incidence of adverse surgical events was similar between treatment groups, even after the follow-up period of each RECORD study (30-35 days after the last dose of the study drug). ${ }^{8,9}$ In the open-label XAMOS study, the incidence of postprocedural wound discharge was higher in the rivaroxabantreatment group compared with the SOC group, ${ }^{11}$ which was not seen in the double-blind Phase III studies. This reported increase could be at least in part attributed to the so-called "Weber effect": an increased reporting of adverse events for new drugs during their first few years on the market. ${ }^{28}$ To support this consideration, it is important to note that the more objective end point of "bleeding that leads to reoperation" was not increased with rivaroxaban compared with SOC in XAMOS. ${ }^{11}$

In ORTHO-TEP, patients treated with rivaroxaban experienced fewer surgical complications requiring revision surgery $(1.15 \%$ versus $3.68 \%, P<0.001)$ (Table 2 ) and a shorter length of hospitalization ( 8.3 days versus 11.1 days) than those treated with LMWH, suggesting that complications with rivaroxaban in these patients were less severe than with LMWH. ${ }^{17}$ The reduction in length of hospital stay in rivaroxaban-treated patients compared with LMWH was especially pronounced in patients with postsurgical complications, which also indicates that complications in rivaroxaban-treated patients were less severe (Figures 1 and 2). Other smaller, single-center studies have reported no significant difference in wound complications between rivaroxaban- and SOC-treatment groups. ${ }^{14,21,29}$ However, it should also be noted that some real-life studies have reported contrasting results, with an increased reoperation rate for wound-related problems in patients treated with rivaroxaban compared with LMWH..$^{12,13,30}$ These complications can be defined as returning to the operating room for open irrigation and debridement of a wound $\leq 30$ days after the initial operation. ${ }^{12}$ Owing to small sample sizes, these small, real-life, observational studies are often underpowered, which restricts the meaningful conclusions that can be derived. ${ }^{19}$ Results of these studies are summarized in Table 3.

Although the evidence regarding wound complications during rivaroxaban thromboprophylaxis may seem conflicting, it is important to note that higher rates were not detected in studies of higher evidence levels (four randomized controlled trials). ${ }^{8,9}$ Large prospective or retrospective mono- or multicentric registries have presented mixed results. Whereas XAMOS revealed 
A

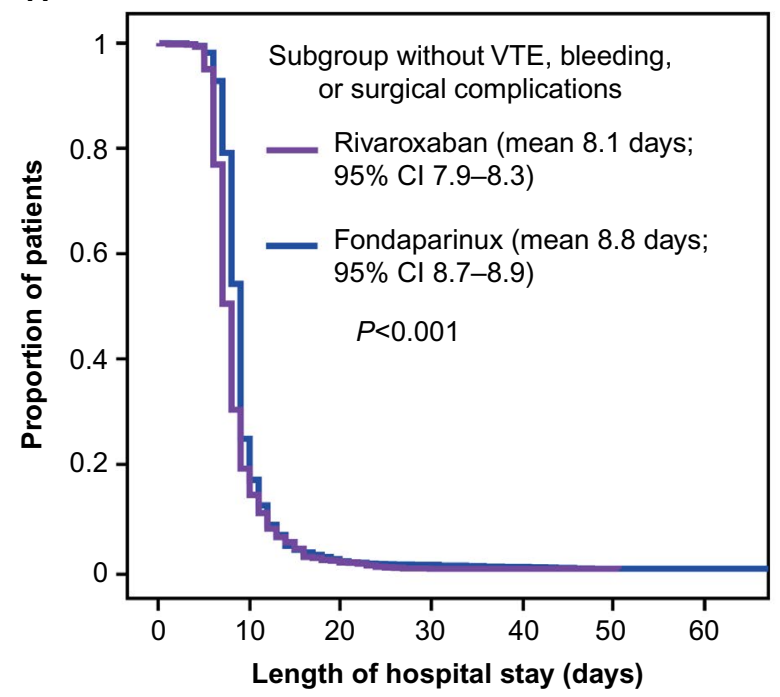

C

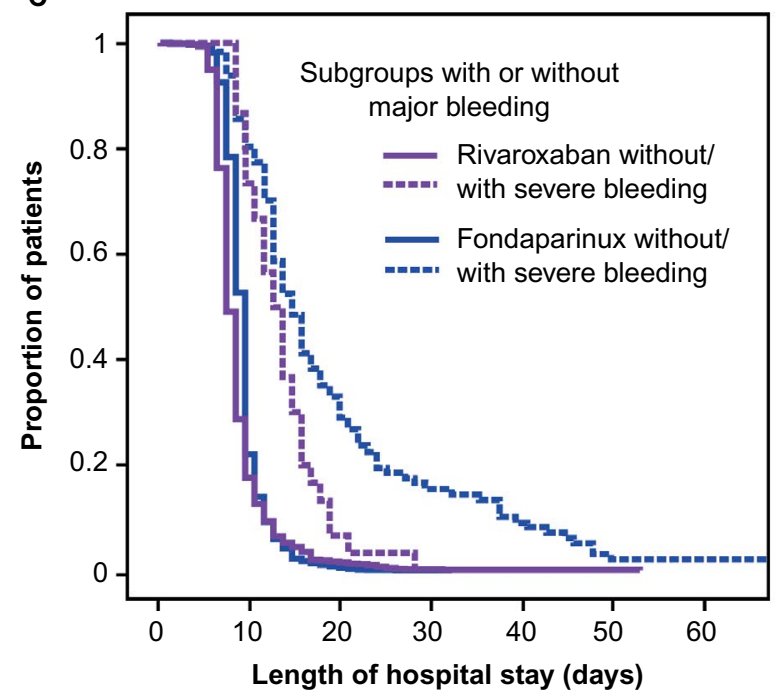

B

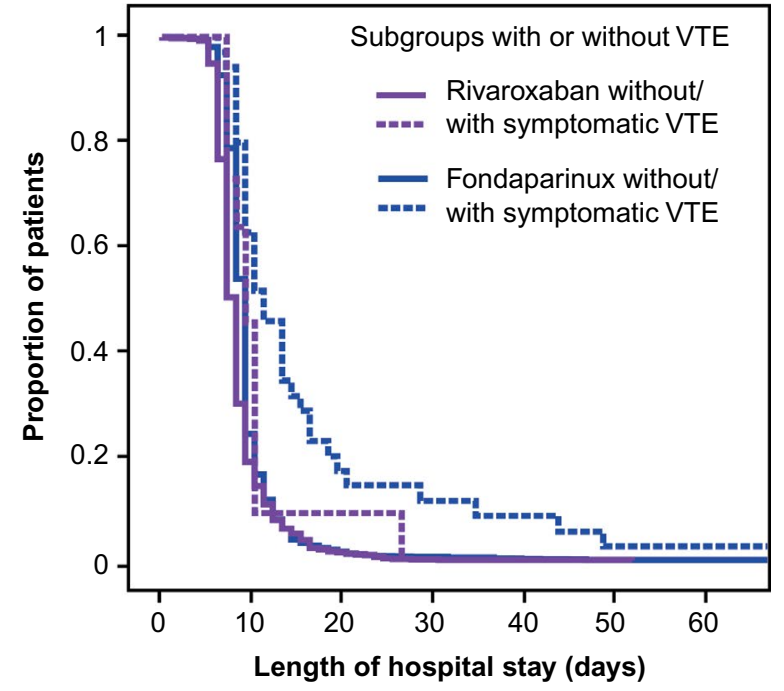

D

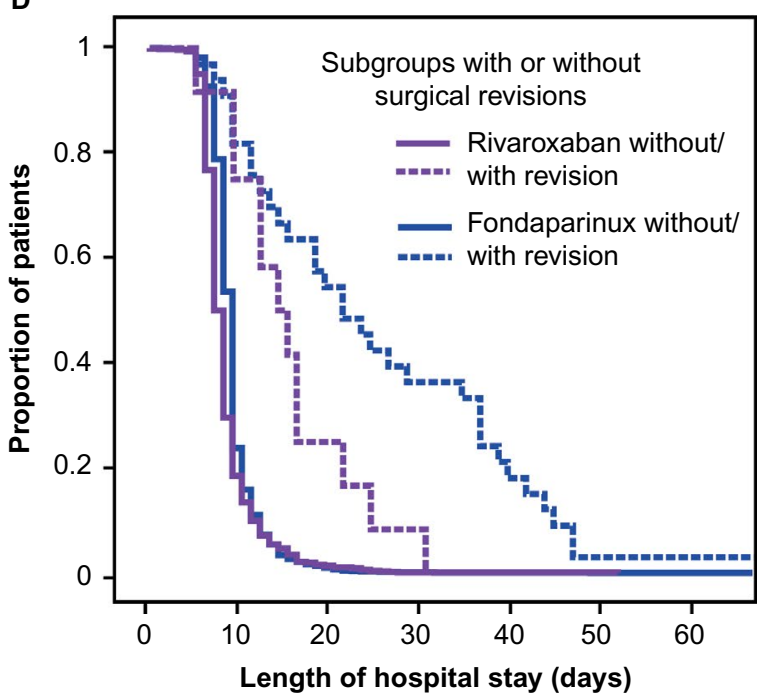

Figure I Kaplan-Meier analysis of length of hospital stay with rivaroxaban and fondaparinux.

Notes: Subgroups of patients without complications (A), with and without VTE (B), with and without major bleeding (C), and with and without surgical revisions (D). Owing to the interference of complications and confounding factors over time, these analyses are of a descriptive nature only, and were not assessed for statistical significance. Adapted with permission from the Journal of Thrombosis and Haemostasis (John Wiley \& Sons Ltd, Chichester, UK). Beyer-Westendorf J, Lützner J, Donath L, et al. Efficacy and safety of rivaroxaban or fondaparinux thromboprophylaxis in major orthopedic surgery: findings from the ORTHO-TEP registry. 2012;10(I0):2045-2052. () 2012 International Society on Thrombosis and Haemostasis. ${ }^{16}$

Abbreviations: $\mathrm{Cl}$, confidence interval; VTE, venous thromboembolism.

a higher incidence of treatment-emergent postprocedural wound discharge in the rivaroxaban group, ORTHO-TEP did not report conclusively on wound-related complications. ${ }^{11,16,17}$ Other real-life studies have indicated increased wound-healing problems in rivaroxaban-treatment groups. . $^{12,13,30}$

\section{Timing of first dose of thromboprophylaxis}

The incidence of bleeding or venous thromboembolic events may be influenced by the timing of thromboprophylaxis initiation. Optimizing the dosing schedule by initiating anticoagulation at the most appropriate time after surgery can have substantial differences in VTE-risk reduction in patients. ${ }^{31}$ Subcutaneous injections need to be delayed by $\geq 6$ hours postsurgery for optimal therapeutic benefit. ${ }^{32}$ For this reason, in the RECORD studies the first dose of rivaroxaban was administered after 6 hours (ie, provided hemostasis was established), with the original protocol stating that rivaroxaban should be initiated within 6-8 hours after surgery. Even within a clinical study, this timeline was not always achieved, and most patients received the drug 6-10 hours after surgery. Across the 
A

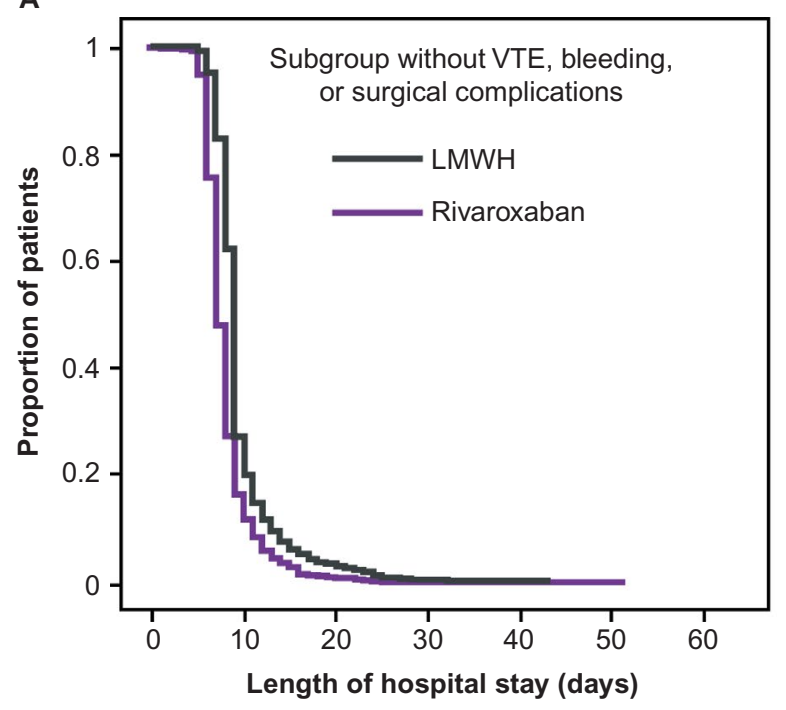

C

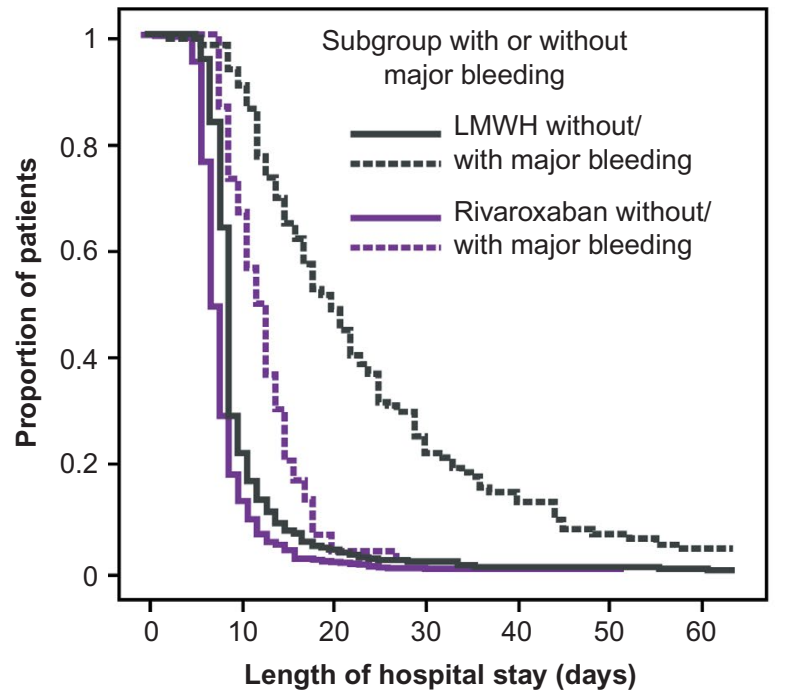

B

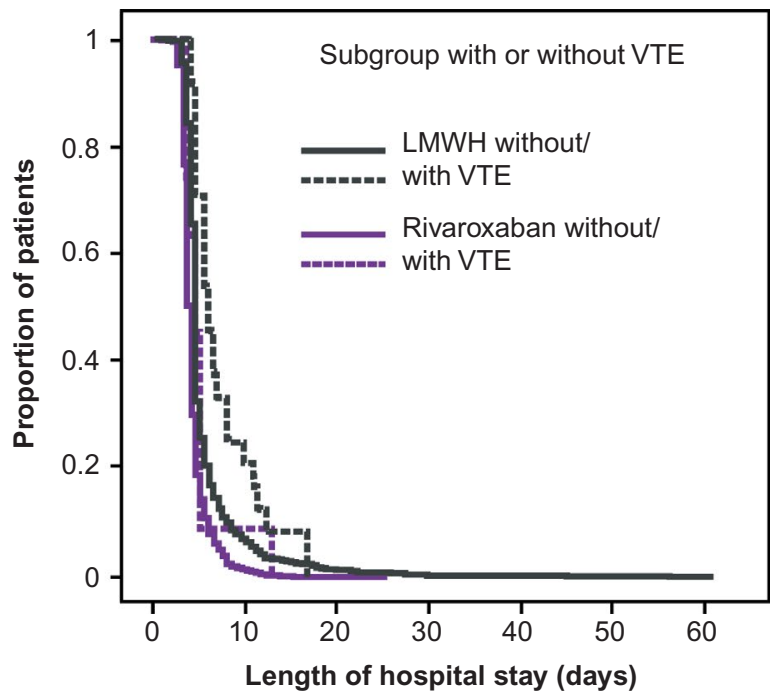

D

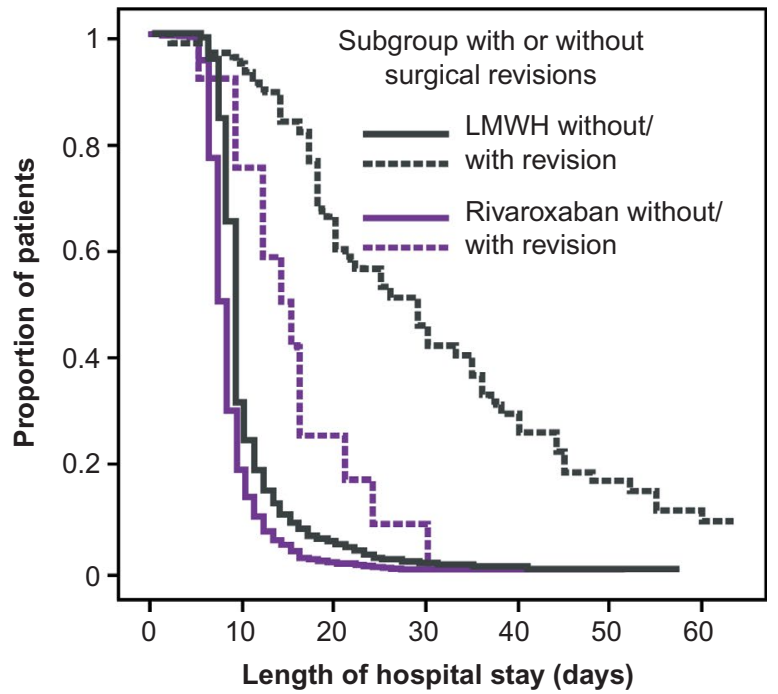

Figure 2 Kaplan-Meier analysis of length of hospital stay with rivaroxaban and LMWH.

Notes: Subgroups of patients without complications (A), with and without VTE (B), with and without major bleeding (C), and with and without surgical revisions (D). Owing to the interference of complications and confounding factors over time, these analyses are of a descriptive nature only, and were not assessed for statistical significance. Adapted with permission from the Journal of Thrombosis and Haemostasis (Schattauer Publishers, Stuttgart, Germany). Beyer-Westendorf J, Lützner J, Donath L, et al. Efficacy and safety of thromboprophylaxis with low-molecular-weight heparin or rivaroxaban in hip and knee replacement surgery: findings from the ORTHO-TEP registry. 2013;109(I):154-163. ( Schattauer Publishers, Stuttgart. ${ }^{17}$

Abbreviations: LMWH, low-molecular-weight heparin; VTE, venous thromboembolism.

four RECORD studies, it was found that rivaroxaban given after surgery resulted in a reduction in the rate of VTE and allcause mortality compared with enoxaparin started the evening before surgery $(0.6 \%$ versus $1.3 \%)$. No significant differences in major bleeding were observed between the rivaroxaban and enoxaparin regimens. ${ }^{8}$

In XAMOS, the 6-10-hour postoperative initiation of rivaroxaban was successful in reducing the incidence of symptomatic VTE compared with SOC; ${ }^{11} 57 \%$ of rivaroxaban patients received their first dose $>6-10$ hours postsurgery, ${ }^{11}$ and later initiation ( $>10-24$ hours after surgery) of rivaroxaban treatment had no adverse effects on efficacy or safety the morning after surgery. ${ }^{33}$ The median time of the first dose was $\sim 8$ hours after surgery and was similar between the two treatment groups. ${ }^{11}$ Antithrombotic benefits of rivaroxaban were maintained in all patients who received their first rivaroxaban dose up to 24 hours after surgery. There was no evidence that early initiation of rivaroxaban increased the risk of bleeding, but this observation was based on data from a very small number of patients who took their first dose earlier than the recommended 
time window. ${ }^{33}$ Other studies demonstrated that the initiation of VTE prophylaxis on the day after surgery was effective, thus allowing for a broader time window in which to begin rivaroxaban therapy. ${ }^{21}$ It is currently recommended that the first dose of rivaroxaban be taken 6-10 hours after surgery, providing hemostasis has been established. ${ }^{34}$

\section{Type of anesthesia}

Regional anesthesia, particularly spinal and epidural anesthesia, is often used in lower-limb orthopedic surgery and is associated with a low risk of epidural hematoma. This risk is increased 15-fold by concomitant use of pharmacologic thromboprophylaxis in the perioperative period if appropriate precautions are not taken. ${ }^{35}$ In XAMOS, neuraxial anesthesia was used more often than other types of anesthesia (such as general), a pattern that was consistent with the RECORD studies. ${ }^{8,11,36}$ There were no spinal hematomas in rivaroxabantreated patients in either the Phase III RECORD studies ( 0 of 6,183 patients) or the noninterventional XAMOS study ( 0 of 8,778 patients). ${ }^{36,37}$ The incidence of total VTE plus all-cause mortality was unaffected by the type of anesthesia used in RECORD, ${ }^{37}$ a finding supported in real-life practice in XAMOS, which showed a consistently favorable benefit-risk profile for rivaroxaban irrespective of whether general or neuraxial anesthesia was employed. ${ }^{11}$ Study results confirm that the effectiveness of rivaroxaban compared with SOC is unaffected by the type of anesthesia used in patients undergoing elective hip or knee arthroplasty.

\section{Patients with renal impairment}

Analysis of the RECORD Phase III studies showed that renal impairment and the use of the rivaroxaban $10 \mathrm{mg}$ once-daily dose did not result in increased rates of VTE or major bleeding in relation to the comparator in more than 2,500 patients with creatinine clearance $(\mathrm{CrCl}) \leq 80 \mathrm{~mL} / \mathrm{min}^{8}{ }^{8}$ This is not surprising, because rivaroxaban plasma levels in renal impairment are only moderately higher compared with those in healthy volunteers after the administration of a single $10 \mathrm{mg}$ oral dose: the area under the plasma concentration-time curve increases 1.44 -fold ( $90 \%$ confidence interval [CI] 1.1-1.9) in patients with mild ( $\mathrm{CrCl} 50-79 \mathrm{~mL} / \mathrm{min})$, 1.52-fold (90\% CI 1.2-2) in patients with moderate $(\mathrm{CrCl}$ $30-49 \mathrm{~mL} / \mathrm{min})$, and 1.64-fold (90\% CI 1.2-2.2) in patients with severe $(\mathrm{CrCl}<30 \mathrm{~mL} / \mathrm{min})$ renal impairment, respectively. ${ }^{38}$ No dose adjustments are needed for mild or moderate renal impairment in patients undergoing elective hip or knee arthroplasty. ${ }^{34}$ Rivaroxaban is not recommended in patients with $\mathrm{CrCl}<15 \mathrm{~mL} / \mathrm{min}$ and should be used with caution in those with severe renal impairment $(\mathrm{CrCl}=15-29 \mathrm{~mL} / \mathrm{min})$.

\section{Periprocedural management of therapeutic rivaroxaban dosages}

Increasing use of rivaroxaban for long-term or chronic indications, such as stroke prevention in patients with nonvalvular $\mathrm{AF}$, means that clinicians are encountering a growing number of patients who need elective or emergency surgery but are already receiving rivaroxaban. Experience and data on the periprocedural management of these patients are limited, but attempts have been made to establish guidelines on periprocedural management for those already receiving rivaroxaban. ${ }^{39,40}$ An evaluation of the periprocedural management of these patients found that although interventional procedures were common in anticoagulated patients, complication rates were low and fatal complications rare..$^{39}$ The European Heart Rhythm Association has published a guidance paper on periprocedural management of patients with AF treated with NOACs, including the use of rivaroxaban. ${ }^{41}$

Findings from the Dresden NOAC registry demonstrated that the periprocedural management of rivaroxaban is simple and safe, because its pharmacologic profile allows for short interruptions. ${ }^{39}$ However, the authors demonstrated that the use of therapeutic dosages of heparin for "bridging" - a step not routinely required when interrupting rivaroxaban treatment - significantly increases the risk of major periprocedural bleeding complications.

\section{Impact on health economics}

Although the principal concern of physicians is their patients' welfare, it is also important to be aware of the health care costs associated with VTE after surgery, because thromboprophylaxis can result in significant resource expenditure. Early cost-effectiveness analyses have shown that owing to the high economic burden of VTE on the health care system, thromboprophylaxis use is cost-effective compared with no prophylaxis. ${ }^{42}$ Economic analyses based on the RECORD studies have shown that rivaroxaban has the potential to reduce the cost of treatment by US $\$ 82$ compared with SOC in THR and by $\$ 284$ in TKA. These significant cost savings are primarily driven by a reduction in costs associated with hospitalization for symptomatic events. Greater savings with rivaroxaban were also observed when the cost of home-nurse time or training time for self-administration of enoxaparin were included. ${ }^{43,44}$ In XAMOS, the median duration of hospitalization was $\sim 11$ days in both the rivaroxaban and SOC groups (length of stay varied between regions, and the mean length of stay in Europe was 9 days). ${ }^{11}$

Data from ORTHO-TEP showed that the mean length of hospital stay after surgery was significantly shorter with rivaroxaban (8.3 days) compared with fondaparinux (9.3 days, 
$P<0.001){ }^{16}$ and LMWH (11.1 days, $\left.P<0.001\right),{ }^{17}$ and that this result was driven mainly by the reduction in adverse event rates and severity seen in the rivaroxaban cohort (Figures 1 and 2). Furthermore, a retrospective cohort study that investigated patients $(n=2,050)$ treated for lower-extremity fractures in an orthopedic and trauma department over a 3-year period found similar results, with a mean length of hospital stay of 12.2 days in the rivaroxaban group compared with 13.1 days in the SOC group $(P=0.016) .{ }^{45}$ Collectively, these studies support the view of a reduction in patient-treatment costs with rivaroxaban. ${ }^{44}$

\section{Trauma-related fractures}

The risk of VTE in patients undergoing lower-limb fracturerelated major orthopedic surgery is substantial: the incidence of venographically detected DVT after hip-fracture surgery is estimated at approximately $50 \%$, of which $27 \%$ is proximal DVT. ${ }^{1,46}$ Despite this high risk, data on thromboprophylaxis after fracture-related orthopedic surgery are mainly confined to Phase III studies of the safety and efficacy of LMWH and fondaparinux after hip-fracture or lower-limb fracture surgery patients. ${ }^{47}$ In a multicenter, randomized study of 5-day prophylaxis after hip-fracture surgery with fondaparinux and enoxaparin, the rates of VTE were $8.3 \%$ and $19.1 \%$, respectively, with no difference in the incidence of major bleeding ( $2.2 \%$ versus $2.3 \%){ }^{48}$

Some countries that participated in XAMOS have a wider label that allows the use of rivaroxaban for thromboprophylaxis after lower-limb fracture surgery. An analysis of 790 patients with lower-limb fracture from XAMOS and a XAMOS extension study (XAMOS-Extra) showed that rivaroxaban was associated with a low incidence of symptomatic thromboembolic and bleeding events, either similar to or numerically lower than those seen in patients receiving SOC. ${ }^{49}$ The overall incidence of symptomatic VTE in the rivaroxaban-treatment group was $0.57 \%$, compared with $1.14 \%$ with SOC. A low incidence of wound complications and other adverse events was also observed. Patients with hip/femoral fracture (median age 73 years) who received rivaroxaban had a lower risk of treatment-emergent serious adverse events compared with those receiving SOC (odds ratio $0.26,95 \%$ CI $0.07-0.88$ ), although this effect was less marked in patients with lower-leg fractures (median age 48 years, odds ratio $0.52,95 \% \mathrm{CI} 0.18-1.47$ ). ${ }^{49}$

A small study involving 84 patients assessed rivaroxaban thromboprophylaxis in patients after pelvic trauma and found that treatment with rivaroxaban did not increase postoperative bleeding in surgical wounds, and decreased the overall incidence of DVT when administered within 24 hours of injury or 24 hours after hemodynamic stabilization. ${ }^{21}$ These positive initial studies point toward the safety and effectiveness of rivaroxaban when used for VTE prevention in trauma-related fracture patients. However, in most countries rivaroxaban is currently not approved for VTE prophylaxis in fracture patients, and further studies in this field are needed. At this point, off-label use of rivaroxaban cannot be recommended.

\section{Conclusion}

Valuable clinical information on rivaroxaban in VTE prevention after major orthopedic surgery has been obtained from studies performed as part of routine clinical practice. The Phase III RECORD program demonstrated the efficacy and safety of rivaroxaban $10 \mathrm{mg}$ once-daily thromboprophylaxis after THA/TKA surgery. XAMOS, ORTHO-TEP, and a Canadian retrospective study (together involving a total of over 45,000 patients), in addition to a number of real-life experience studies of varying size and design, have reinforced these findings by establishing the safety and effectiveness of rivaroxaban $10 \mathrm{mg}$ once daily in everyday patient care. These real-life studies observing patients receiving thromboprophylaxis have been invaluable in addressing many of the safety concerns physicians and orthopedic surgeons may have regarding the use of rivaroxaban in their patients, and confirm that when rivaroxaban is used according to the label, adverse events remain low versus existing SOC. The EMA has updated the European label for the $10 \mathrm{mg}$ dose of rivaroxaban based on results derived from the XAMOS study, lending further support to the use of rivaroxaban after major orthopedic surgery of the hip and knee.

\section{Acknowledgments}

The authors would like to acknowledge Li Wan, who provided editorial support with funding from Bayer HealthCare Pharmaceuticals and Janssen Scientific Affairs LLC.

\section{Disclosure}

JBW has received honoraria and research support from Bayer HealthCare, Boehringer Ingelheim, Bristol-Myers Squibb, Daiichi Sankyo, and Pfizer. PM has been a consultant for and has received honoraria from Bayer HealthCare, Sanofi, and Bristol-Myers Squibb. AGGT has been a consultant for Bayer HealthCare, Janssen Pharmaceutical Research and Development LLC, Astellas, Portola, and Takeda. The authors report no other conflicts of interest in this work.

\section{References}

1. Geerts WH, Bergqvist D, Pineo GF, et al. Prevention of venous thromboembolism: American College of Chest Physicians evidence-based clinical practice guidelines (8th edition). Chest. 2008;133(6 Suppl): $381 \mathrm{~S}-453 \mathrm{~S}$. 
2. Hamidi V, Ringerike T, Hagen G, Reikvam A, Klemp M. New anticoagulants as thromboprophylaxis after total hip or knee replacement. Int J Technol Assess Health Care. 2013;29(3):234-243.

3. Friedman RJ. New oral anticoagulants for thromboprophylaxis after total hip or knee arthroplasty. Orthopedics. 2009;32(12 Suppl):79-84.

4. Eriksson BI, Borris LC, Friedman RJ, et al. Rivaroxaban versus enoxaparin for thromboprophylaxis after hip arthroplasty. NEngl J Med. 2008; 358(26):2765-2775

5. Kakkar AK, Brenner B, Dahl OE, et al. Extended duration rivaroxaban versus short-term enoxaparin for the prevention of venous thromboembolism after total hip arthroplasty: a double-blind, randomised controlled trial. Lancet. 2008;372(9632):31-39.

6. Lassen MR, Ageno W, Borris LC, et al. Rivaroxaban versus enoxaparin for thromboprophylaxis after total knee arthroplasty. $N$ Engl J Med. 2008;358(26):2776-2786.

7. Turpie AG, Lassen MR, Davidson BL, et al. Rivaroxaban versus enoxaparin for thromboprophylaxis after total knee arthroplasty (RECORD4): a randomised trial. Lancet. 2009;373(9676):1673-1680.

8. Turpie AG, Lassen MR, Eriksson BI, et al. Rivaroxaban for the prevention of venous thromboembolism after hip or knee arthroplasty: pooled analysis of four studies. Thromb Haemost. 2011;105(3):444-453.

9. Lassen MR, Gent M, Kakkar AK, et al. The effects of rivaroxaban on the complications of surgery after total hip or knee replacement: results from the RECORD programme. J Bone Joint Surg Br. 2012;94(11):1573-1578.

10. Frosch P, Decking J, Theis C, Drees P, Schoellner C, Eckardt A. Complications after total knee arthroplasty: a comprehensive report. Acta Orthop Belg. 2004;70(6):565-569.

11. Turpie AG, Haas S, Kreutz R, et al. A non-interventional comparison of rivaroxaban with standard of care for thromboprophylaxis after major orthopaedic surgery in 17,701 patients with propensity score adjustment. Thromb Haemost. 2014;111(1):94-102.

12. Jensen CD, Steval A, Partington PF, Reed MR, Muller SD. Return to theatre following total hip and knee replacement, before and after the introduction of rivaroxaban: a retrospective cohort study. J Bone Joint Surg Br. 2011;93(1):91-95.

13. Jameson SS, Rymaszewska M, James P, et al. Wound complications following rivaroxaban administration: a multicenter comparison with low-molecular-weight heparins for thromboprophylaxis in lower limb arthroplasty. J Bone Joint Surg Am. 2012;94(17):1554-1558.

14. Chahal G, Saithna A, Brewster M, et al. A comparison of complications requiring return to theatre in hip and knee arthroplasty patients taking enoxaparin versus rivaroxaban for thromboprophylaxis. Ortop Traumatol Rehabil. 2013;15(2):125-130.

15. European Medicines Agency. Guideline on clinical investigation of medicinal products for prevention of venous thromboembolism (VTE) in patients undergoing high VTE-risk surgery. 2012. Available from: http:// www.ema.europa.eu/docs/en_GB/document_library/Scientific_guideline/2012/05/WC500127902.pdf. Accessed January 20, 2016.

16. Beyer-Westendorf J, Lützner J, Donath L, et al. Efficacy and safety of rivaroxaban or fondaparinux thromboprophylaxis in major orthopedic surgery: findings from the ORTHO-TEP registry. J Thromb Haemost. 2012;10(10):2045-2052.

17. Beyer-Westendorf J, Lützner J, Donath L, et al. Efficacy and safety of thromboprophylaxis with low-molecular-weight heparin or rivaroxaban in hip and knee replacement surgery: findings from the ORTHO-TEP registry. Thromb Haemost. 2013;109(1):154-163.

18. Lazo-Langner A, Fleet JL, McArthur E, Garg AX. Rivaroxaban vs. low molecular weight heparin for the prevention of venous thromboembolism after hip or knee arthroplasty: a cohort study. J Thromb Haemost. 2014;12(10):1626-1635.

19. Sindali K, Rose B, Soueid H, Jeer P, Saran D, Shrivastava R. Elective hip and knee arthroplasty and the effect of rivaroxaban and enoxaparin thromboprophylaxis on wound healing. Eur J Orthop Surg Traumatol. 2013;23(4):481-486.

20. Heckmann M, Hillebrand I, Silay H, et al. Rivaroxaban superior to nadroparin for thromboprophylaxis in patients receiving hip or knee arthroplasty. J Thromb Haemost. 2013;11(Suppl 3):PB3.46-6.
21. Monzon DG, Iserson KV, Cid A, Vazquez JA. Oral thromboprophylaxis in pelvic trauma: a standardized protocol. J Emerg Med. 2012;43(4): 612-617.

22. Clavé A, Fazilleau F, Dumser D, Lacroix J. Efficacy of tranexamic acid on blood loss after primary cementless total hip replacement with rivaroxaban thromboprophylaxis: a case-control study in 70 patients. Orthop Traumatol Surg Res. 2012;12(5):484-490.

23. Niskanen RO, Korkala OL. Tranexamic acid reduces blood loss in cemented hip arthroplasty: a randomized, double-blind study of 39 patients with osteoarthritis. Acta Orthop. 2005;76(6):829-832.

24. Rajesparan K, Biant LC, Ahmad M, Field RE. The effect of an intravenous bolus of tranexamic acid on blood loss in total hip replacement. J Bone Joint Surg Br. 2009;91(6):776-783.

25. Beyer-Westendorf J, Förster K, Pannach S, et al. Rates, management, and outcome of rivaroxaban bleeding in daily care: results from the Dresden NOAC Registry. Blood. 2014;124(6):955-962.

26. Linkins LA, Choi PT, Douketis JD. Clinical impact of bleeding in patients taking oral anticoagulant therapy for venous thromboembolism: a meta-analysis. Ann Intern Med. 2003;139(11):893-900.

27. Gomes T, Mamdani MM, Holbrook AM, Paterson JM, Hellings C, Juurlink DN. Rates of hemorrhage during warfarin therapy for atrial fibrillation. CMAJ. 2013;185(2):E121-E127.

28. Weber JC. Epidemiology of adverse reactions to nonsteroidal antiinflammatory drugs. In: Rainsford KD, Velo GP, editors. Advances in Inflammatory Research. New York: Raven Press; 1984:1-7.

29. Yen SH, Lin PC, Kuo FC, Wang JW. Thromboprophylaxis after minimally invasive total knee arthroplasty: a comparison of rivaroxaban and enoxaparin. Biomed J. 2014;37(4):199-204.

30. Rath NK. The use of rivaroxaban for chemical thromboprophylaxis following total knee replacement. Knee. 2013;20(6):397-400.

31. Eriksson BI, Quinlan DJ. Oral anticoagulants in development: focus on thromboprophylaxis in patients undergoing orthopaedic surgery. Drugs. 2006;66(11):1411-1429.

32. Turpie A, Bauer K, Eriksson B, Lassen M. Efficacy and safety of fondaparinux in major orthopedic surgery according to the timing of its first administration. Thromb Haemost. 2003;90(2):364-366.

33. Haas S. Rivaroxaban or standard thromboprophylaxis in routine clinical practice: outcomes by time to anticoagulant initiation in the XAMOS study. Oral presentation at: European Federation of National Associations of Orthopaedics and Traumatology 2014 Annual Meeting; June 4-6, 2014; London, UK. Available from: http://efort.conference2web. com/content/3479/details?from_view=all\&view_address=search\%3D haas\%26events\%3D3. Accessed July 27, 2016.

34. Bayer Pharma AG. Xarelto (rivaroxaban) [summary of product characteristics]. 2015. Available from: http://www.ema.europa.eu/docs/en_GB/ document_library/EPAR_-_Product_Information/human/000944/ WC500057108.pdf. Accessed March 21, 2016.

35. Rosencher N, Bonnet MP, Sessler DI. Selected new antithrombotic agents and neuraxial anaesthesia for major orthopaedic surgery: management strategies. Anaesthesia. 2007;62(11):1154-1160.

36. Haas S, Holberg G, Kreutz R, Lassen MR, Mantovani L, Turpie AG. Rivaroxaban or conventional thromboprophylaxis in routine clinical care: subgroup analysis of the XAMOS study by types of anesthesia used. Abstract A100 presented at: ASRA 38th Annual Regional Anesthesia and Acute Pain Medicine Meeting; May 2-5 2013; Boston, MA.

37. Rosencher N, Llau JV, Mueck W, Loewe A, Berkowitz SD, Homering M. Incidence of neuraxial haematoma after total hip or knee surgery: RECORD programme (rivaroxaban vs. enoxaparin). Acta Anaesthesiol Scand. 2013;57(5):565-572.

38. Kubitza D, Becka M, Mueck W, et al. Effects of renal impairment on the pharmacokinetics, pharmacodynamics and safety of rivaroxaban, an oral, direct factor Xa inhibitor. Br J Clin Pharmacol. 2010;70(5):703-712.

39. Beyer-Westendorf J, Gelbricht V, Forster K, et al. Peri-interventional management of novel oral anticoagulants in daily care: results from the prospective Dresden NOAC registry. Eur Heart J. 2014;35(28):1888-1896.

40. Turpie AG, Kreutz R, Llau J, Norrving B, Haas S. Management consensus guidance for the use of rivaroxaban - an oral, direct Factor Xa inhibitor. Thromb Haemost. 2012;108(5):876-886. 
41. Heidbuchel H, Verhamme P, Alings M, et al. European Heart Rhythm Association practical guide on the use of new oral anticoagulants in patients with non-valvular atrial fibrillation. Europace. 2013;15(5): 625-651.

42. Oster G, Tuden RL, Colditz GA. A cost-effectiveness analysis of prophylaxis against deep-vein thrombosis in major orthopedic surgery. JAMA. 1987;257(2):203-208.

43. Kwong LM, Duran A, Diamantopoulos A, Sengupta N, Lees M. Costeffectiveness of rivaroxaban for prevention of venous thromboembolism (VTE) after total hip or knee replacement (THR, TKR) in the US. J Thromb Haemost. 2009; 7(Suppl 2):787.

44. Friedman RJ, Sengupta N, Lees M. Economic impact of venous thromboembolism after hip and knee arthroplasty: potential impact of rivaroxaban. Expert Rev Pharmacoecon Outcomes Res. 2011;11(3) 299-306.

45. Long A, Zhang L, Zhang Y, et al. Efficacy and safety of rivaroxaban versus low-molecular-weight heparin therapy in patients with lower limb fractures. J Thromb Thrombolysis. 2014;38(3):229-305.
46. McNamara I, Sharma A, Prevost T, Parker M. Symptomatic venous thromboembolism following a hip fracture. Acta Orthop. 2009;80(6) 687-692.

47. Falck-Ytter Y, Francis CW, Johanson NA, et al. Prevention of VTE in orthopedic surgery patients: Antithrombotic Therapy and Prevention of Thrombosis, 9th ed - American College of Chest Physicians evidence-based clinical practice guidelines. Chest. 2012;141(2 Suppl): e278S-e325S

48. Eriksson BI, Bauer KA, Lassen MR, Turpie AG. Fondaparinux compared with enoxaparin for the prevention of venous thromboembolism after hip-fracture surgery. N Engl J Med. 2001;345(18):1298-1304.

49. Lassen MR, Haas S, Kreutz R, Mantovani LG, Holberg G, Turpie AG. Rivaroxaban for thromboprophylaxis after fracture-related orthopedic surgery in routine clinical practice. Clin Appl Thromb Hemost. 2016; 22(2):138-146.

50. Muñoa L, González AB, Díaz de Rada P, Valentí A, Valentí JR. Rivaroxaban is as efficient and safe as bemiparin as thromboprophylaxis in knee arthroscopy. Musculoskelet Surg. 2014;98(1):21-25.
Orthopedic Research and Reviews

\section{Publish your work in this journal}

Orthopedic Research and Reviews is an international, peer-reviewed, open access journal that focusing on the patho-physiology of the musculoskeletal system, trauma, surgery and other corrective interventions to restore mobility and function. Advances in new technologies, materials, techniques and pharmacological agents are particularly

\section{Dovepress}

welcome. The manuscript management system is completely online and includes a very quick and fair peer-review system, which is all easy to use. Visit http://www.dovepress.com/testimonials.php to read real quotes from published authors. 